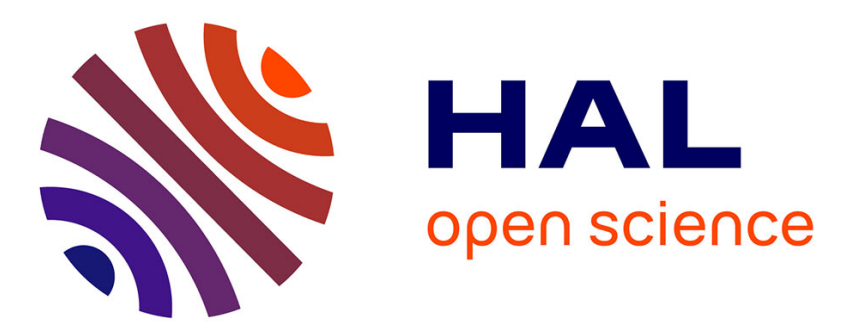

\title{
Overview of research related to science in society in Europe
}

Giulia Anichini, Suzanne de Cheveigné

\section{To cite this version:}

Giulia Anichini, Suzanne de Cheveigné. Overview of research related to science in society in Europe. Science and public policy, 2012, Science in Society in Europe, 39 (6), pp.701-709. $10.1093 / \mathrm{scipol} / \mathrm{scs} 088$. hal-02943138

\section{HAL Id: hal-02943138 \\ https://hal.science/hal-02943138}

Submitted on 1 Jan 2021

HAL is a multi-disciplinary open access archive for the deposit and dissemination of scientific research documents, whether they are published or not. The documents may come from teaching and research institutions in France or abroad, or from public or private research centers.
L'archive ouverte pluridisciplinaire HAL, est destinée au dépôt et à la diffusion de documents scientifiques de niveau recherche, publiés ou non, émanant des établissements d'enseignement et de recherche français ou étrangers, des laboratoires publics ou privés. 
Author's version of:

Overview of research related to science in society in Europe

Giulia Anichini et Suzanne de Cheveigné

Science and Public Policy (2012) 39(6): 701-709

\title{
Overview of research related to science in society in Europe
}

\author{
Giulia Anichini, EHESS, and Suzanne de Cheveignéi, CNRS, \\ Centre Norbert Elias, \\ 2 rue de la Charité, 13236 Marseille Cedex, France \\ (suzanne.de-cheveigné@univ-amu.fr, +33 4911407 61)
}

\begin{abstract}
We have carried out a cross-sectional analysis of the information on research in the "Science in Society" (SiS) field collected by the MASIS (Monitoring Policy and Research Activities on Science In Society in Europe) project. Based on the reports set up by national correspondents in the different countries, we were able to provide a picture of the type of research being carried out in Europe under national funding. It has provided a new picture, bringing in countries that do not often appear in the mainstream literature. A typology of countries has been set up according to their activity in the area and a description of research topics is provided. A number of integrated projects, sometimes cross-national, that examine a topic under different angles appear particularly promising. Most available information concerned dedicated SIS research projects - very little was available on SiS research "embedded" in projects centred on other "hard-science" topics.
\end{abstract}

\section{Introduction}

The relations between science and society have been the object of much attention in Europe over the past decades. They often worry policy-makers who have to confront public scares or just plain distrust on the part of citizens and consumers. The European Commission (EC) has played an active role in promoting reflection and experimentation in the area. New modes of interaction have developed between science and society, allowing greater participation of citizens and more public debate even if such practices are not totally widespread over Europe. Furthermore, the EC is not the only actor in the field and research is also funded at the national level. In the face of this complex and evolving situation, social science research is direly needed to understand what is going on and what is at stake.

In the present contribution, we aim to provide a picture of what research is taking place in Europe at this national level, based on an overview of the information concerning research in the "Science in Society" (SiS) field collected by the MASIS (Monitoring Policy and Research Activities on Science In Society in Europe) project (see the introduction to this issue). Our analysis has been made possible by the collective effort of nearly 40 colleagues who assembled and compiled their national data - we are greatly indebted to them. Within the national reports, information on $\mathrm{SiS}$ research was missing only from a few countries. As one might expect, this data-gathering exercise has provided very interesting information, even though $\mathrm{SiS}$ issues are not always easy to define or identify. Collating it all was a challenge, as was interpreting the inevitably synthetic national reports. In the face of numerous examples of very interesting SiS 
research projects, we could mention only a few (many more references can be found in the national reports). We have often made fairly bold categorisations and evaluations, hoping in this way to create opportunities for reflexion and discussion by pointing out recurring patterns and even attempting to build a typology of countries.

Beyond the inevitable risks and limitations of such a collective information gathering exercise - of which a further discussion can be found in the introduction to this issue - we would like to point out that this type of meta-analysis provides an innovative point of view on the field. By construction, all countries are treated equally and this allows information that rarely finds its way into the international academic literature to emerge. The barriers that usually prevent this can be language problems or lack of contacts for national researchers who do not travel a lot. A glance at the author lists of some recent books illustrates our point. These are important books that allow voices from many countries to be heard. But for example in the Handbook of Public Communication of Science and Technology (Bucchi and Trench, 2008), 12 out of 19 authors come from only three countries, Italy, the UK and the USA. In Bauer and Bucchi's Journalism, Science and Society, 20 out of 32 authors come from 4 countries, Brazil, Italy, the UK and the US. In The Culture of Science (Bauer, Shukla and Allum, 2012), 25 authors out of 42 come from 5 countries, Brazil, China, India, the UK and the USA. The three books have opened their pages widely and the other authors take us all around the world - it is also interesting to note that the "centre of gravity" is moving. But we suggest that it is also instructive to create the conditions to systematically hear about all counties, in the present case restricted to Europe. ii This approach means that we shall be providing a different picture from the one that Science in Society scholars are used to. It will not be a review of the literature in the field - an exercise that books like the ones mentioned above greatly contribute to. On the contrary, it will be an attempt to stand in the shoes of national researchers in Europe, to see the questions they are interested in, to understand the research environment they are rooted in and finally to ask whether the strong disparities they face are really inevitable.

Science in society themes are very diverse and they are evolving. Ever since the beginnings of modern science, epistemological, philosophical and ethical questions have been brought under discussion. Over the past forty years, more pragmatic sociological questions have been raised concerning both the perceptions and attitudes of the public (Miller, 1983; Bauer et al, 2007; Bauer, 2009), as well as the communication of science topics (Bucchi and Trench, 2008). Then, more recently, newer issues related to the economy, the sociological dynamics and the politics of science and technology arose (Bijker, 1987; Traweek, 1988; Knorr-Certina, 1999; Novotny et al., 2001, Jasanoff, 2004; Pestre, 2007 to quote a few important stages). The unification of these very different issues under the single label of "Science in Society questions" is even more recent. We shall of course find traces of this long history among the activities in the different countries that we are analyzing.

In what follows, we shall first describe the information-gathering process that took place under the MASIS project concerning our topic, since it conditioned the data we have analyzed. We shall give a general overview of the types of research that have been reported and attempt the perilous exercise of building a typology of countries according to the way they support and fund work in the SiS area. Then, we shall go into greater detail analyzing different areas of research, pointing out some elements that we feel are particularly interesting and innovative and, whenever possible, suggesting synergies. Finally, after discussing fundings budget, we shall attempt to draw a number of conclusions. In what follows, unless otherwise indicated, all information provided concerning each country is taken from its MASIS profile. 


\section{An overview of European SiS research at the national level}

The present analysis, as we said, is based on the information provided by the national correspondents taking part in the MASIS project. The consequences of this type of data collection are discussed in the introduction to this issue. We shall simply comment on points specific to our topic here. The precise wording of the instructions they followed is provided in annexe. On the one hand, the correspondents were asked to provide information on research activities specifically focused on SiS topics and, on the other, to provide information about research on SiS issues that might be "embedded" in research projects focused on other issues - for instance, a work package on SiS issues within a project on nanotechnology. Within the first category, correspondents were asked to say whether any specific SiS research programmes had been running in their countries over the period 2006-2010. They were asked to describe 5 to 8 projects - this, in many cases, meant selecting only a few among many - and to point out what they felt were the main trends in the field. For the majority of countries, information could be provided on these points, for instance concerning research on perceptions, science communication or education, governance or ethics of science and technology. On the other hand, information concerning "embedded" SiS research was much less readily available, very few countries keeping any kind of database on the question. Finally, the correspondents were asked to what extent SiS issues are taken up as evaluative elements in national research programs - how are public outreach and dialogue strategies, efforts to attract young people towards science or formalized procedures for taking on board ethical issues or gender balance taken into account in evaluation of research proposals? On these last issues, policy statements were often available but effective practices were much less easy to gauge.

Reading through the national contributions to the MASIS project concerning SiS research, a first clear distinction appears between countries that have longer traditions of research and development and ones that are actively trying to build new knowledge-production systems. The topics they develop are not the same and the available resources are very different. Beyond that, we were able to make a distinction between countries that massively invest in SiS research and others for which it is given lower priority with fewer human and financial resources being allocated. Based on such differences and insomuch as sufficient information is available, we have attempted to propose a typology of these countries that differ both by the content and by the mode of organisation of their SiS research (see table 1). It is doubtlessly schematic, but does allow us to draw a first panorama of the SiS landscape before going into more detail about the type of research carried out. We believe it also can provide food for thought about SiS research policy-making throughout Europe. 


\begin{tabular}{|c|c|c|}
\hline $\begin{array}{l}\text { Major players in } \\
\text { SiS research }\end{array}$ & $\begin{array}{l}\text { Countries in which SiS research is highly developed. } \\
\text { Numerous projects are running and specific funding is } \\
\text { available. Very diverse topics are under study, civil society } \\
\text { issues are very present. }\end{array}$ & $\begin{array}{l}\text { Germany } \\
\text { Netherlands } \\
\text { United } \\
\text { Kingdom } \\
=== \\
\text { Austria } \\
\text { Norway } \\
\text { Switzerland }\end{array}$ \\
\hline $\begin{array}{l}\text { Smaller-but- } \\
\text { active players in } \\
\text { SiS research }\end{array}$ & $\begin{array}{l}\text { Far fewer resources than the previous group, less organized } \\
\text { but particularly innovative and varied approaches. }\end{array}$ & $\begin{array}{l}\text { Croatia } \\
\text { Ireland } \\
\text { Portugal } \\
\text { Slovenia }\end{array}$ \\
\hline $\begin{array}{l}\text { Countries with } \\
\text { dispersed SiS } \\
\text { research }\end{array}$ & $\begin{array}{l}\text { Quite a lot of SiS research activity but very dispersed. } \\
\text { Weakly institutionalized with no or few dedicated centres, } \\
\text { no or few specific funding programs. }\end{array}$ & $\begin{array}{l}\text { Denmark } \\
\text { France } \\
\text { Iceland } \\
\text { Spain } \\
\text { Sweden } \\
\text { Israel } \\
\text { Italy }\end{array}$ \\
\hline $\begin{array}{l}\text { Countries } \\
\text { building a new } \\
\text { research system }\end{array}$ & $\begin{array}{l}\text { Countries with developing research systems. SiS research } \\
\text { mostly focused on education, organizing research (policy, } \\
\text { management) and some science communication. }\end{array}$ & $\begin{array}{l}\text { Albania } \\
\text { Bulgaria } \\
\text { Cyprus } \\
\text { Lithuania } \\
\text { Luxemburg } \\
\text { Poland } \\
\text { Serbia } \\
\text { Slovakia } \\
\text { Turkey }\end{array}$ \\
\hline
\end{tabular}

Table 1. SiS research situations in European countries. ${ }^{\text {iii }}$

Some countries are massively investing the SiS field, carrying out varied types of research, much of it innovative, supported by solid and well coordinated institutional structures and funding programs (see Table 1). We can even attempt a further ranking among this group of "major players in SiS research", with three really outstandingly active countries, the Netherlands, the United Kingdom and Germany and three close runners-up, Switzerland, Austria and Norway. The first three in particular - and the others too, up to a certain point - are old industrialized countries and technoscience has long played a major role in their development. These countries have set up specific programs for the analysis of the societal implications of science and technology and provided the corresponding funding schemes. Large coordinated research programmes have been set up and dedicated research centres exist (for instance, the Netherland reports three of them). Among the innovative topics that researchers approach, there are issues related to research methods or innovation and technological development. Civil society is very present and issues such as the social impact of technologies, public participation in scientific choices or uses of technical devices by social groups appear frequently in the research these countries carry out.

We then distinguished a group of smaller countries that appear to be exploring particularly promising issues in very interesting ways in spite of restricted resources - we call them the "smaller-but-active 
players in SiS research". They develop a lot of innovative issues, often concerning the participation of civil society in research policy and practice. This group includes Croatia, Ireland, Portugal and Slovenia.

Among the other countries, a number of quite large ones carry out a fair amount of active SiS research but in a dispersed manner with few or no organized SiS research centres and few or no dedicated funding programs. We shall call them "countries with dispersed SiS research". The general impression is that the SiS research sector receives relatively weak support from science and technology policy-makers there, in spite of the fact that these countries have long research traditions and considerable resources. Issues in these countries are diverse and can be quite innovative, turning on ethics, perceptions of science, science governance, participation, etc. This group includes Denmark, France, Iceland, Israel, Italy, Spain and Sweden (this last country being a specific case because SiS research appears to be receding).

Finally, the countries building new research systems have specific priorities and problems in the SiS area. Among them, we find nations that used to be part of the Eastern block (Albania, Bulgaria, Lithuania, Poland, Serbia, Slovakia), some smaller southern European countries (Cyprus, Turkey) as well as Luxemburg that has only recently developed its own university. In these countries, many of the main issues are related to the development of human resources - education, attracting youth (and in some cases women) to science and the problem of "brain drain". Indeed, many of these countries have either had their researchers trained abroad or seen them move away at a later stage and are anxious to have them return to develop the national research effort. The other main issues concern the organization and governance of their newly developing research systems as well as ethical issues. Although EU funding is outside the scope of the present study, it should be noted that it is often referred to in the reports on these countries since, in practice, it provides them with the structural framework of their SiS research. Europe is not only the major financial source of such research but it also orients it towards new topics. For many of these countries, it plays a major role in the development of the SiS field.

Our typology is obviously schematic but it clearly distinguishes between, on the one hand, countries that are putting a massive effort into SiS research per se and on the other those whose immediate priority is (re)building a research and development system, to which SiS research is more subordinated. In between these two extremes, a few countries, in spite of limited resources, are making a remarkable effort. Unfortunately, policy-makers in quite a large group of countries do not appear to consider the issue to be of first order importance.

In the following two sections we shall examine main research topics the SiS research fields, beginning with topics that concern more specifically the relations between the scientific and the public: science education, science communication and public perceptions of science. We shall then turn to questions that relate more to the internal functioning of the scientific institution, concerning the governance of science including ethics. In each case, we shall provide some examples of interesting research projects going on in the area.

\section{Research on science and the public}

This first group of SiS topics - science education, science communication and public perceptions of science - includes topics that have been under scrutiny for many decades. They cover basic preoccupations of both scientists and policy-makers.

\section{Science education and the "brain drain"}


Science education is a basic preoccupation of many governments when they are trying to develop national research and innovation but are confronted with a lack of the necessary human resources. Linked to that is the question of "brain drain", when skilled young people, educated in the country or abroad, decide not to establish themselves in their mother country, thereby reducing the available workforce. Women are also frequently seen as a major potential source of human resources. This preoccupation with education is a frequent phenomenon in the "new-research-system" countries that are building their research systems and critically need people to run it. In Croatia, for instance, research is carried out on the national education curriculum to determine what knowledge, skills and abilities children and students need in order to respond to demands of the future.

Concerning human resources and "brain drain", an ambitious transnational collaboration analyzed "Catching up Societies in Transition Female Highly-Skilled Migration and Youth Drain from South East Europe to Austria in the Context of EU Enlargement"iv. The goal of this project was to study the flow of potential researchers between "sending countries" (Bulgaria, Romania, Bosnia and Herzegovina, Croatia) and "receiving countries" (Austria) and all were partners in the project. Single countries such as Albania, Germany, Lithuania, Montenegro and Slovenia also run projects on the topic of brain drain. Science communication, particularly in the media, is often mobilized with the aim of solving that problem. The notion of "knowledge society" is often invoked, specially in countries that recently joined the EU. Questions revolve around the tools of communication, assessment and education raised in the new social contexts, the skills promoted in Europe, the actors and the modalities followed in the innovation process, the system of national research and it's integration into the European space.

\section{Science communication}

In nearly all countries research is carried out on science communication, particularly on media discourse about science. Much of it is topic-oriented, mainly towards health, climate change, genetics or nanotechnology and is conceived of as a way of monitoring the way these issues circulate in the public sphere. For example, a number of countries are involved in the study of media representations of nanotechnology, obviously an emerging issue. For instance, in Denmark, Great Britain and Finland projects studying the media coverage in national contexts, specifying potential danger, benefits, interest and new opportunities expected in the field.

The building of long data time-series is an important issue in media research. For example, in Spain, a long-term national project has been studying the press coverage related to medicine and health, going back to $1997^{\mathrm{v}}$. It focuses annually on a specific theme and also includes the study of international media, aiming to be an important sociological tool to help understand the social impact of health concerns in Spain and in an international context.

An innovative Austrian project aims to follow the media process all the way from production to reception but focussing on a specific topic, synthetic biology. Funded by the program on life sciences GEN-AU ELSA III and called CISYNBIO ${ }^{\text {vi }}$ (Cinema and Synthetic Biology), its aim is to analyze how synthetic biology is represented by film-makers, what are the recurrent images associated to the representation of this discipline and how they are understood by the public.

Another new development of research on media coverage of science topics is the study of its impact on scientists. For instance, in Switzerland, a research project on "The public communication on climate change in Switzerland and its impact on science" seeks to understand the relationship between science 
and the public, including the way media discourse impacts the choice and definition of research problems.

Most of the science communication research mentioned in the national reports concerns the press, or, less frequently, television with a few projects concerning other vectors such as science museums (Austria) or science journals (Croatia). Unfortunately, little research appears to be carried out on the audiences of science communication, for instance on the way they read the press, use the Internet or watch television (which was still, in 2007, the major source of science information according to the Eurobarometer on "Scientific research in the media"viii). It often seems to be taken for granted that media communication will have strong and direct impact on the public - a presumption that mainstream communication research has long shown to be incorrect (Livingstone, 2005; Couldry et al, 2010).

\section{Public perceptions of science}

For many countries, the surveying of public perceptions of science is a central issue. To contextualize this research carried out at a national level, one should recall that several international survey instruments focus on science and technology questions, the foremost of which, in the European context, is the Eurobarometer, with specific surveys on science and technology, biotechnology and nanotechnology, climate change, energy, etc ${ }^{\mathrm{ix}}$. Other international surveys such as the World Values Survey ${ }^{\mathrm{x}}$ or the International Social Survey Programme ${ }^{\mathrm{xi}}$ also touch on S\&T issues.

Nevertheless, many countries also carry out research in this field on the national level. Often, researchers focus their attention on specific scientific fields such as biotechnology, the environment or nanotechnology. Such topic-oriented surveys can be found for instance in Austria (on genomics), Italy (DNA and forensic science), the Netherlands (DNA and identity), Portugal (health, environment or again DNA and forensic science) or the United Kingdom (environmental risk, GMOs). To address emerging technologies that scientists have not yet been able to identify their future consequences, especially their implications for human health and their impact on the environment, the notion of "risk" is widely used. The concept can be mobilized in order to explore public practices and representations as well as management and policy-making issues. While some technologies are explored primarily via the notion of risk, others affecting for example new medical practices, the field of genomics or biometrics, lead to more complex ethical and sociological questions concerning the redefinition of human beings, the control of individuals or the preservation of human biological material.

A new and important dimension that is being explored is the link between perceptions and actual practices. For instance, a project carried out in Switzerland seeks to understand how people read and interpret the labels of chemical products and how they take into account the toxicity of these in their daily activities $^{\text {xii }}$. To do so, researchers analyzed the perceptions, knowledge and behaviour of the population, also observing the daily handling of household chemicals in the home and interviewing people.

This first major domaine that includes the three topics of science education, science communication and perceptions of science and technology has now become quite traditional in the SiS field. Some of the more innovative research in these areas links the different issues, for instance studying both media discourse and perceptions. More research along these lines would no doubt be useful, for instance linking education issues to perceptions of science (and, more pragmatically, to career choices) or testing more closely the often unquestioned idea of the impact of media discourse on public perceptions.

\section{$4 \quad$ Research on governance and ethics of science and technology}


This second major area of research touches on the ways in which the scientific institution is governed and controlled by society.

\section{Governance of science}

Generally speaking, the topic of "governance" is a fairly recent area of development of SiS issues, appearing under the pressure of shrinking resources and new demands for better management and more accountability in the use of resources. Clearly, the times when the scientific community "naturally" governed itself are revolved and all sorts of questions concerning policy choices, evaluation of research or the participation of civil society are brought under scrutiny. This research can concern many areas of policy making. Just to quote a few examples, in Finland, several institutions work on questions such as science and innovation policy, the strategic management of innovations, the regulation of technological risks, participatory approaches for technology assessment, uses of research results by public and private sector, the influence of policy on scientific orientations and social interactions. Croatian researchers work on knowledge management technologies and on the innovation system, comparing Croatia to other European countries. The country also develops projects focused on scientists and the social organization of science, including studies of networking and the "social ecology" of knowledge production systems. Slovenia runs a project comparing the evaluation of research project proposals according to the peer review system and to bibliometric methods. Portugal carries out research on Science, Technology and the Law.

A good deal of research is carried out on the participation of citizens in decision-making. Pressure from increasingly well-educated citizens on the one hand and an active EU policy in support of taking civil society on board on the other (particularly under the 6th Framework programme) have caused an increase in research on participatory forms of governance and the implication of the population in science and technology issues. Among many possible examples, we find research in Ireland on public engagement in policy decision-making concerning nanotechnology and studies on environmental governance in Sweden concerning the relationship between different stakeholders involved in the exploitation of marine resources of a fragile ecosystem like Baltic sea ${ }^{\text {xiii }}$. In the United Kingdom, we also find several projects examining the role of civil society actors in environmental governance. Researching socio-technical controversies in general, an interesting comparison of the effectiveness of two tools for decision-making is being lead by a Portuguese team and concerns the choice of the location of the new Lisbon airport and the extension of Milan airport.

Another aspect that is related to the governance of science is the relationship between scientific research and business or industry. Norway has an ongoing research project within the framework of an "actionoriented" program primarily geared towards the identification of the needs of the public sector, industry and interest groups ${ }^{\mathrm{xiv}}$. In Slovenia an analysis of the role of "intermediary scientific organizations" such as technological centres, technological parks, technological clusters, centres of competence or university innovation incubators in processes of commercialisation of academic research results is being carried out. Bulgaria runs a project on the "Optimization and application of models and tools to intensify interaction between science and business in support of strong and competitive Bulgarian industry". In Finland, a large research programme ran from 2001 to 2005 and funded 40 research projects to study the interaction between technology, industry and society. Generally speaking, however, the topic of business and industry is not very present in the national reports - this may be a reflection on the academic origin of most of the correspondents but it may also say that these issues are not receiving a great deal of scrutiny. Relatively speaking, the newer EU member states seem to be more attentive to the question. 


\section{Ethics in $S \& T$}

Another line of investigation on science in society, shared by most countries, is the exploration of ethical questions regarding the evolution of science and technology. The legitimacy of scientific knowledge, the boundaries between good and bad practice, the role of science and its place in society are all important aspects of this reflection on the responsibility of science. For instance, in Poland a number of projects are devoted to reflections on the role of science and its value system. Many projects are focused on specific technologies. The ethical aspects of research and applications in the field of nanotechnology are being studied in Belgium or in Norway where a project is exploring the importance of "trust". Medical issues receive much attention with research on the limits of biomedical research, the procedures for the production and storage of genetic and proteomic data or the rules for recruiting subjects for research purposes. In Italy, several projects are focused on ethical and legal issues that emerge in medical practice and stem cell research and its legal, ethical and clinical consequences are being studied in Belgium, the Netherlands, Switzerland and the United Kingdom.

A large number of ethics research projects focus on genetics. In Austria a project on the ethical dimensions of prenatal genetic testing seeks to understand the decisions that people make, under the hypothesis that the choice is not always limited to the individual but it is a shared responsibility. A research project for example is set up to explore the diffusion of genetic testing in Austrian medical practice. ${ }^{\mathrm{xv}}$ Another project, part of the same research program, analyzes the way the life sciences integrate ethical demands and how they cope with them, under the assumption that the society influences the direction followed by scientists in elaboration of knowledge ${ }^{x v i}$. Austria, Finland and Germany participate in a project which explores, among other questions, the ethical aspects of DNA analysis in defining families, to understand how genetic testing is involved in immigration policies ${ }^{\text {xvii }}$. In Italy, research is carried out on genetic counselling and in the Netherlands a project concern the way people react to the possibility of predicting the chances of developing a specific disease. All these projects obviously raise important ethical issues ranging from the protection of privacy to the definition of parenthood as considered only in biological terms.

\section{Equality and social inclusion in science}

Another important issue related to the way science develops as a social institution within society is that of equality among the people who work there. Strangely, the topic of gender was explicitly excluded from the MASIS remit by the EC, since a lot of work on such questions had already been funded by the Commission. But trying to put to one side a major issue in the Science and society "galaxy" was not easy, since it is closely linked to many others (youth, governance, etc.). A number of national correspondents apparently felt that this was difficult and they provided quite a lot of information on the question. Unfortunately, it has not been collected systematically so we shall not develop it further here. The interested reader might nevertheless refer to the national profiles of Iceland, Ireland, Norway or Spain for some examples of innovative research projects on gender equality in research. On the other hand, no projects on ethnic diversity in research have been mentioned in the national reports and nor is the issue very present in the literature (Blake and Lavalle, 2000 is an exception) - this is clearly a serious blind spot in SiS research.

\section{Funding for research on Science in Society}


Relatively few countries have set up large and permanent funding programs on Science in Society issues - they are among what we have called the "Major players in SiS research " (see Table 1). Thus, Austria, Germany, the Netherlands or Switzerland run programs that distribute several million Euros per year. On the other extreme, for many countries the only funder of such research remains the EU: although they are outside of MASIS's scope, it should be recalled that DG Research's Framework Programmes for Research and Technological Development have provided major impulse in the field.

Data concerning the amounts of funding was not provided for many countries and what is given is not always sufficiently precise to allow comparison (for instance, project durations are not always given so normalizing to the amount of funding per year is not possible). However it is clear, as could be expected, that there are strong differences between countries: in some, project budgets are measured in tens of thousands of Euros while in others they are in hundreds of thousands of Euros. Funders include public research institutes, centres of excellence, ministries (education, culture), agencies or academies. Private foundations also fund research on SiS issues.

Very little information was available on SiS research "embedded" in projects centred on other "hardscience" aspects of a topic. This is unfortunate since this type of collaborative research can be an interesting way to develop strongly interdisciplinary approaches - although there is a risk that such projects only "pay lip-service", as one national correspondent put it, to SiS questions or only ask the social scientists to ensure the "acceptability" or the "dissemination" of whatever is being developed by the "hard scientists". A wider picture of such collaborations would clearly be useful.

\section{Final remarks and questions}

One particularly promising trend that we have observed is the development of transnational projects where countries collaborate and compare their situations. On an intermediate scale compared to many EU funded projects they are often focussed on a precise question (like some of the projects mentioned above: Austria, Bulgaria, Bosnia and Herzegovina, Croatia and Romania on brain drain in science or Austria, Germany and Finland on genetic testing involved in immigration policies). This is an efficient way to pool restricted resources - a strategy Austria seems to have developed particularly thoroughly. Such an approach could no doubt be further developed in many other countries, since, beyond the pragmatic argument of shared costs, international comparisons run on a tractable scale can be methodologically very fruitful.

Integrated, multidimensional programs, where large resources converge on one topic and many aspects of the question are studied in a coordinated manner, also appear to be particularly productive. We met several examples in the country reports. Austria has set up a massive one on genetics that takes into account ethical, legal and social implications of genome research. The topics covered are very diverse, including genetic testing, biobanks, pharmacogenomics, and the governance of biomedical research, DNA and immigration, biotechnology and gender. The United Kingdom's Economic and Social Research Council, besides running a general SiS programme, has created a specific network on genomics covering a wide range of research on the social implications of genomics including plant and animal genetics, embryonic stem cell research, and health applications. Both in Ireland and in the Netherlands, large technology assessment program are devoted to the SiS issues around nanotechnology such as the social aspects of nanotechnology in the life sciences, public engagement, nanotechnology and sustainability, images of nanotechnology, methods to map the sociotechnical dynamics of nanotechnology, 
"nanodistricts" (i.e. the geography of nanotechnology research). Israel runs an interdisciplinary funding program on health and the environment. So-called "embedded" projects where SiS issues are integrated into projects that focus on other types of research on a given issue can be a way of building multidimensional projects. A Norwegian project entitled "Reflexive Systems Biology: towards an Appreciation of Biological, Scientific and Ethical Complexity" provides a promising example.

Concerning the issues under study, biomedicine and particularly genomics are very present, with nanotechnology moving into the public arena too. SiS questions in the field of climate change do not yet appear to be as thoroughly investigated, though a number of countries are reported to be investigating the question (Austria, Belgium, Germany, Israel, Norway, Portugal, Switzerland, Turkey and the United Kingdom). Other topics are nearly absent from the national reports: research concerning nuclear energy is reported only in Germany and Romania - this is likely to change after the Fukushima accident. Research on biometrics in relation to security questions is reported only in Cyprus. History of science has rarely been mentioned (except in France and Ireland) - possibly because it is not always considered as part of the SiS sphere .

In summary, the material provided by national correspondents in the MASIS project has proved to be a rich source of information on research being carried out on SiS questions at the national level. It has allowed us to draw a new picture of SiS research, bringing in countries that do not often appear in the mainstream literature. A variety of topics could be analyzed and general trends appeared in the research specifically dedicated to SiS, with some countries powerfully carrying forward the issue. They provide interesting examples of what an active national policy in the field can produce - and what EC policy can encourage under schemes to coordinate action at national level, such as ERA-Net. On the other hand, the picture of what kind of SiS research is "embedded" in research projects focused on other topics was much less clear - it would be very useful if more systematic data collecting took place. Our general feeling, however, is quite optimistic: SiS issues are gaining in importance and increasingly appearing as elements of evaluation of research policy in general. 


\section{Bibliography}

Bauer, Martin (2009) The evolution of public understanding of science - discourse and comparative evidence. Science, technology and society, 14(2), 221-240

Bauer, Martin, Nick Allum and Steve Miller (2007) What can we learn from 25 years of PUS Survey research? Liberating and expanding the agenda, Public Understanding of Science $16: 79-95$

Bijker, Wiebe E., Thomas P. Hughes, and Trevor J. Pinch (eds.) (1987) The Social Construction of Technological Systems: New Directions in the Sociology and History of Technology, Cambridge, Massachusetts: The MIT Press, Publications

Blake, Margaret and Ivana La Valle (2000) Who Applies for Research Funding? Key factors shaping funding application behaviour among women and men in British higher education institutions. London : The Wellcome Trust.

Bucchi, Massimiano and Brian Trench (eds) (2008), Handbook of Public Communication of Science and Technology, London: Routledge

Couldry, Nick, Sonia Livingstone and Tim Markham (2007/2010) Media Consumption and Public Engagement. Beyond the Presumption of Attention, London: Palgrave Macmillan

Knorr-Cetina Karine. (1999) Epistemic cultures: how the sciences make knowledge, Cambridge, Harvard University Press.

Livingstone, Sonia (ed.) (2005) Audiences and Publics: When Cultural Engagement Matters for the Public Sphere, Bristol, Intellect

Miller, Jon D. (1983) Scientific Literacy: A Conceptual and Empirical Review, Daedalus, 112 : 29-48

Pestre, Dominique (2007) Historical Perspectives on Science, Society and the Political, Report to the Science, Economy and Society Directorate, European Commission

Traweek Sharon. (1988) Beamtimes and Lifetimes, the World of High Energy Physicists, Cambridge, Mass., Harvard University Press

Novotny, Helga, Peter Scott, and Michel Gibbons (2001) Re-Thinking Science: Knowledge and the Public in an Age of Uncertainty Cambridge:Polity

Sheila Jasanoff (2004) States of knowledge, The Co-production of Science and Social Order London: Routledge 


\section{Annexe: extracts from MASIS guidelines}

In the following questions, there is a distinction between SiS research on the one hand, and $\mathrm{SiS}$ issues embedded in mainstream research on the other hand. SiS research are those studies particularly targeting public understanding of science, governance of science, science policy, science education, science communication, women in science, ethics in science and technology, the reciprocal relations of science and culture, young people and science, and similar issues. But SiS issues may also be present in other research activities, in which the main objectives of research are not SiS related issues, but in which $\mathrm{SiS}$ practices or perspectives are embedded. This could include studies within the natural sciences applying innovative or extensive use of public involvement in the research process, new ways of communicating research results, ambitious efforts to bring in ethical and societal issues into research, innovative ways of involving a variety of stakeholders (politicians, NGOs, industry, social scientists) etc. Such efforts are referred to as research, in which SiS issues are embedded.

Please list the 5-8 most important research project (or larger programmes of empirical research involving several sub-projects), ongoing or completed within the last 5 years, in which the research is directly concerned with SiS issues (importance in terms of budget size, scientific quality, innovation or political/scientific impact).

Based on the list above, and your knowledge of the field, what seems to be emerging themes and crosscutting issues in current SiS research in your country?

Please describe any current, or recent, research funding programs in your country, specifically targeted at $\mathrm{SiS}$ research.

With regard to research activities, in which the main objectives of research are not SiS related issues, but in which SiS practices or perspectives are embedded, what seems to be emerging trends in how issues related to SiS is being embedded in research activities in your country? Are there any innovative or exemplary ways of embedding SiS practices or perspectives that could be transferred to other countries?

Please describe the extent to which SiS issues are taken up as evaluative elements in national research programs.

Note: we are also looking for the 'relative weight' of such SiS criteria compared to other evaluative criteria (e.g. originality of the proposal; stringency of the argument), the relative importance of SiS criteria vis-à-vis other SiS criteria (is gender balance issues e.g. more dominant than ethical issues in evaluation). Are SiS criteria superficial 'tick the box' or real threshold elements (e.g. women applicants only).

\section{Endnotes :}

\footnotetext{
i AlsoVisiting Senior Research Fellow at London School of Economics.

ii Another example of such an approach, also EU funded, was undertaken in a related field with the Gender and Science database (http://www.genderandscience.org).

iii Countries were not classified when we felt that we did not have sufficient information. This was the case for Belgium, Czech Republic, Estonia, Finland, Greece, Hungary, Latvia, Lichtenstein, Macedonia, Montenegro, Romania.

iv http://personalwesen.univie.ac.at/frauenfoerderung/ueber-uns/archiv/projekte/catching-up-societies-in-transition/

${ }^{v}$ www.fundaciovilacasas.com/es/proyecto_salud/informe_Quiral

vi www.cisynbio.com
} 
viii Special Eurobarometer 282, available at http://ec.europa.eu/public_opinion/archives/eb_special_fr.htm.

ix http://ec.europa.eu/public_opinion/archives/eb_special_fr.htm.

${ }^{x}$ www.worldvaluessurvey.org

${ }^{\mathrm{xi}}$ www.issp.org

xii www.bag.admin.ch/themen/chemikalien/00249/index.html?lang=fr

xiii https://www.chalmers.se/ait/gcplus-en/projects/fishery-governance

xiv http://www.forskningsradet.no/en/Funding/FORFI/1253953470377

${ }^{\mathrm{xv}} \mathrm{http}: / /$ www.gen-au.at/projekt.jsp?projektId=74\&lang=en

${ }^{x v i} \mathrm{http}: / /$ www.gen-au.at/projekt.jsp?projektId=102\&lang=en

xvii www.immigene.eu/ 